\title{
Cloud computing adoption among state universities and colleges in the Philippines: Issues and challenges
}

\author{
Catherine R. Alimboyong ${ }^{1}$, Mardie E. Bucjan² \\ ${ }^{1}$ College of Information Technology Education, Surigao Del Sur State University-Main Campus, Philippines \\ ${ }^{2}$ Graduate School, Surigao Del Sur State University-Main Campus, Philippines
}

\begin{abstract}
Article Info
Article history:

Received Jan 14, 2021

Revised Aug 8, 2021

Accepted Sep 12, 2021

Keywords:

Academic community

Cloud computing

Collaboration event

Educational system

Higher education

ABSTRACT

The emergence of cloud computing (CC) adoption in higher education institutions (HEIs) is considered widespread today. Its growth comes with tremendous benefits and potential risks as well. This paper endeavors to investigate some issues and challenges that influence the adoption of cloud computing among state universities and colleges (SUCs) in the Philippines. A qualitative design was used in the study as it employed multiple case studies approach. Based on the results, this paper establishes two strong factors such as slow internet connection and lack of understanding or awareness of cloud computing. The findings revealed the impact of cloud computing to SUCs is found beneficial to the educational system amidst the global pandemic. Professors can easily upload lessons and teaching materials while students can easily access the materials online, though the challenge lies in the connectivity of internet in the country. Administrators can easily collaborate with the entire academic community and even to its stakeholder's potential for collaboration even if not in face to face. It is a perfect avenue to be productive and efficient which allows all processes be made possible to all members of the entire academic community, may it be students, professors, staff and even other stakeholders.
\end{abstract}

This is an open access article under the $\underline{C C B Y-S A}$ license.

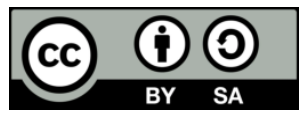

Corresponding Author:

Catherine R. Alimboyong

College of Information Tecnology Education

Surigao Del Sur State University-Main Campus

Rosario, Tandag, 8300 Surigao del Sur, Philippines

Email: catherinealimboyong@gmail.com

\section{INTRODUCTION}

The adaptability of cloud computing (CC) has been a major technological trend over the past few years [1] and is now regarded as a modern technology that provides a significant benefit to higher education institutions [2], [3]. This technology has been adopted by both public and private schools over the years due to its benefits such as flexibility, collaboration, cost-effectiveness, scalability, and others. Because of this, many universities have chosen to implement this technology. However, this expansion has presented endusers with some serious problems and challenges [4]. This paper seeks to explore and analyze significant issues and problems facing cloud computing adoption especially at state universities and colleges in the region, within the context of the education system.

Cloud services are considered to be key elements of both internet-based management and delivery. Likewise, previous studies [5], [6] stated that cloud services are adopted currently worldwide in different fields (e.g., education, business, tourism, scientific information, public and private). It provided numerous significant advantages not only for the information and technology (IT) sectors, but also for academic 
institutions, as well as to all government and private corporations by offering limitless storage and huge processing power capacity. Cloud technology also enables companies and academic institutions to outsource their data at a minimum cost [7]-[9].

Ashtari and Eydgahi [3] stated that cloud technology adoption has confirmed that access to education is well facilitated. Moreover, Almazroi, Shen, and Mohammed [9] described that because of the tremendous resources on the internet, $\mathrm{CC}$ is more practical than the conventional approach to education. A study conducted by Juma and Tjahyanto [10] revealed that security consistently rated first and is regarded as the most serious problem to CC. Thus, in order to take full advantage of this technology, it is therefore important to understand how to address these problems. Previous research indicated that CC adoption has been challenging in academic institutions. Additionally, few reports have been conducted on the problems and difficulties associated with cloud deployment in a school environment where this technology has been implemented. Firstly, unpredictable downtime, it can happen when the provider maintains the server or when unforeseen failures occur [4], [11]. Secondly, as software is remotely accessed, it is understood that it is not controllable. Thirdly, the training of end-users as faculty, staff and administrators is not adequately supported [3], [6]. Fourth, internal resistance, government funding is being reduced [12], [13] lack of infrastructure specialist, and lack of confidence in security [14], [15].

For educators and students in higher education, the benefits of cloud computing are an attractive option. Surprisingly, cloud computing adoption is rapidly increasing [16], [17]. The majority of institutions are migrating their computing platforms on-premises to the cloud. As previously stated, cloud computing is further streamlined by the provision of various providers to academic system for free or at a low cost [10]. Tashkandi and Al-Jabri [18] claimed that the adoption of cloud computing, particularly in Saudi Arabia, has offered them to have access to technology that requires less expertise and costs. Ashtari and Eydgahi [3] examined that conventional teaching and learning approaches are displaced by cloud computing. Despite the significant advantage, it still conveyed various types of issues such as internal policies, data security and data privacy. Some organizations continue to be resistant to cloud adoption due to significant factors such as costs, institutional pressures and changing benefits [19]-[21].

In another study by Das and Dayal [22], they discovered that the most well-known risks associated with cloud computing deployment are data availability and the possibility of data compromise. To ensure a successful deployment, users should carefully review the policies governing the cloud computing model they adopt, including data protection and security. Previous study shows that unmet technological requirements, lowered customer service standards, and security concerns are the most important reasons companies abandon the cloud [2]. Akin, Fagbola, Daramola [15] stated that in similar circumstances, some schools function as: admissions, registration, courses offered. These processes, however, are accomplished through the use of the cloud. Vu, Hartley, Kankanhalli [17] highlighted the importance of the main drivers of cloud computing adoption were not technical in nature, but rather political, social and economic; other issues include a lack of experience, a lack of trust in security, and internal resistance. Sabi, et al. [19] affirmed that IT executives were polled to assess the benefits and drawbacks of cloud computing. Their findings revealed that perceived risks were related to performance, corporate policy compliance, and security, while perceived opportunities were cost savings, flexibility, and quality improvement. Consequently, Branco, Soares, and Rivero [1] stated that when it comes to cloud computing, there are a number of challenges and opportunities to consider. These barriers include those related to availability, reliability, data sharing, licensing, security, capacity, transfer of data, performance, reliability, scalability, and service-level agreements.

On the other hand, previous studies [3], [23] noted that one of the distinct advantages of the cloud to users is its availability and ease of access. The study confirmed that cloud computing is significantly advantageous through the use of computer hardware, mobile devices, university facilities, or a combination of these options at any time or place. However, while the aforementioned potential benefits of cloud computing for higher learning environments have been mentioned, barriers to cloud computing have arisen, such as security and privacy. Furthermore, the technology dependability and performance still remain a challenge.

Based on the information obtained from the literature, to what degree universities are adopting cloud computing has yet to be thoroughly investigated. As a result, there is a lack of understanding and knowledge available to universities in the Philippines, particularly in the region, about the issues and challenges associated with cloud adoption. This research also hopes to make a significant contribution to the growing body of study in the field of cloud computing in a school setting by identifying the factors preventing cloud adoption in state universities and colleges (SUCs) in the Philippines. This paper aims to address the following research questions in order to fill the aforementioned knowledge gap: i) What are the major advantages associated with university's cloud computing adoption?; ii) What are the issues and challenges that are impeding the implementation and use of $\mathrm{CC}$ at the university level?; iii) What are the main factors or barriers to deciding on cloud adoption in the university? 
While the majority of the studies outlined in this article were carried out in private entities. The objective of this research is to explore CC problems and challenges within the framework of a state university, specifically in the provinces of Caraga Region, Philippines. An investigation was performed among IT managers, IT professors and IT professionals in state universities and colleges throughout the region that has gradually migrated to the cloud. The research focuses on the key issues and challenges that have arisen as a result of the use of cloud computing.

\section{RESEARCH METHOD}

\subsection{Research design}

The study employed a qualitative design. Furthermore, the multiple case studies approach of Yin [24] was used to fully understand the factors influencing the use of cloud computing among the SUCs in the region. Interviews are a commonly accepted approach to quality research in order to obtain a thorough knowledge of the context and phenomenon involved. In this study, face-to-face interviews are selected to get detailed insights about the challenges of SUCs cloud adoption. Semi-structured and transparent open-ended questions is also used to enable respondents to fully share their views, ideas and insights into cloud adoption.

\subsection{Questionnaire development}

The study produced two different versions of the research guide questions. The first question was sent by email to key informants to assist interviewees in being more prepared for questions prior to the interview, while the complete set was kept. The following approaches were used to classify the questions: behavioral or operational readiness, physical infrastructure set-up, and personal thoughts.

\subsection{Sample selection}

The selection of participants was based on the inclusion criteria laid down in Table 1 by the researchers. There were three IT leaders from University 1, one IT faculty from University 2, and two IT program leaders from University 3 constitute the study population. Six interviewees were asked to participate in the survey. The study is based in the Caraga area of three SUCs. All of them are financed by the national government as the universities and colleges. The three universities operate similarly because they provide students with graduates and postgraduates curricular programs. University 1 is a state university with six satellite campuses, while University 2 is a state university with two satellite campuses, University 3 is a state college and is currently an applicant for a state university, with two satellite campuses. The interviews were conducted between January 2019 and February 2019 with all identified respondents from the three universities to ensure they covered the necessary details. Informal interviews to obtain exact information were also carried out.

Table 1. The profile of the interviewees

\begin{tabular}{cccc}
\hline SUCs & University 1 & University 2 & University 3 \\
\hline Country of location/Region & Philippines/Caraga & Philippines/Caraga & Philippines/Caraga \\
Type of HEI & SUC & SUC & State college \\
Type of education offered & Graduate and post graduate & Graduate and post graduate & Graduate and post graduate \\
Number of campuses & 6 & 2 & 2 \\
University designation & IT Heads & IT Faculty & IT Head \\
\hline
\end{tabular}

\subsection{Data collection, validity and reliability}

This paper represents the three SUCs as University 1, University 2, and University 3 in order to ensure confidentiality. In interviews with the respondents, a detailed overview of the subject was carried out. The study took a number of approaches using case studies from Yin [24] which have been demonstrated to reduce interviewer opinions to a low minimum in order to produce a good and reliable collection of data. For each interview, tape-to-face interviews are recorded for about 1 to 1 1/2 hours. For analysis, these surveys have been transcribed so that no information is lost. The interviewees had to check the conclusions drawn from each interview for the validity of these interviews.

\section{RESULTS AND DISCUSSION}

\subsection{Administrative support or readiness}

University 1 is thought to be capable of implementing cloud computing. The interviewee explains that the university costs the web hosting company each year because the university does not currently have a cloud-based server. The university makes use of an information system that can be accessed locally. Only the 
following government agencies have access to the budget office, Human Resource Management Office (HRMO), and cashier's office: Land Bank of the Philippines (LBP), Civil Service Commission (CSC) and Department of Budget and Management (DBM) on their online platforms in order for them to enter their files for submission to the aforementioned agencies.

She went on to say that the university has taken a methodical approach to cloud computing adoption. In addition to the information systems used, the university has its own website and a web administrator who is in charge of all data and information. Furthermore, the university has taken the initiative to establish its own server. In fact, employees are given the opportunity to use new systems and stay up to date on the latest technologies as a result of this. Finally, as shown in the transcript, the interviewee expresses her opinion:

"To educate employees who are not tech savvy is a big challenge to the university as it will take more time and effort for them to learn this new process."

The IT faculty at University 2 claims that their faculty and staff have been using cloud services such as email, social media, e-learning systems (Schoology, Edmodo, and Moodle), and Google Apps for several years. They have earned the benefits of technology. Given the benefits, the respondent expresses his concern more about the website downtime prospects resulting in data instability and data protection. Since the computer is accessible automatically, the institution has no authority over it. In turn, there is a chance of reverting to retaining paper-based works rather than paperless works. In this scenario, the university can choose not to use cloud computing. As a result, as is typical with many companies, some personnel are unable to adopt this new technology for personal reasons. Therefore, a lack of knowledge of such technologies is one of the principal factors for University 2 to use the cloud fully.

Finally, University 3 also says that cloud computing has offered comprehensive advantages to the university's faculty and personnel, such as the input of customers in real time, connectivity is easy to upload anywhere, wherever and anywhere. This is possible because the university covers the upfront costs as well as the recurring payments for their internet service and Internet Service Providers (ISPs). However, the interviewee went on to say that the university is dealing with an issue with late payments for internet and ISP subscriptions. And it was discovered that missing internet service for several days simply caused individuals to fall behind in their jobs. This happened because public universities must go through different mechanisms, such as public bidding (Republic Act 9184), as a result, the budget release is delayed. Thus, University 3 has been unable to completely implement cloud services.

\subsection{Physical IT infrastructure set-up}

Both Universities 1 and 2 claimed that they have no problems or are dissatisfied with their IT infrastructure as they both have sufficient information and communications technology (ICT) resources. This is to suggest that cloud implementation has the potential to be effective in their universities. Furthermore, the interviewee at University 1 claims that finances could be a concern due to the lengthy phase of budget release especially in their purchase for IT infrastructures. However, this problem does not completely obstruct cloud deployment. Perhaps as a result of this problem, they continue to value cloud storage, which gives them more freedom to operate when and where they choose. As a result, cloud computing is advancing in this area. University 2 appears to have been using cloud services. However, some of their faculty and staff are also reluctant to embrace cloud technologies due to a lack of awareness and expertise of ICT. Furthermore, others are uninterested in the present state of the university's IT facilities. In comparison, University 3 has had some trouble accepting cloud computing due to a lack of terminals and technological facilities. As a result, the university has had to balance their job such that machine use is on a first come, first served basis.

According to the findings, internet connectivity latency is more important to cloud infrastructure technology adoption. This was brought up in the case of University 3. They were not linked to the secured internet due to the university's restricted capacity in comparison to other universities in the country. This observation is confirmed by a research undertaken by previous researchers [10], [13], [25] affirms that an effective and secure core router between entities and their end users is vital for efficient cloud adoption. In this situation, University 3 was cautious to depend on cloud computing.

Data vulnerability and privacy are another important factor emphasized. This outcome is supported by the previous studies [2], [3], [17], where they confirmed that one of the biggest challenges with CC adoption is security. It is a big concern for University B to move all university data and information to a public or shared cloud server. The university argues that data confidentiality is not guaranteed because the cloud server will be switched off or crash when hackers occur. As a result, it is perceived that security and data privacy concerns could curtail cloud adoption. Furthermore, cloud deployment at University 2 is hampered by a lack of awareness of the cloud. This finding is also supported by various studies [11], [14], 
[25]-[27] that organizations could be exposed to a range of risks for which personnel, rather than processes and other applications, become vulnerable and not ICT knowledge. In this way, the university may subject itself to various risks.

Budget is another consideration in public university cloud decision. Previous researchers [28], [29] affirmed that the adoption of cloud computing necessitates adequate machine and IT infrastructure. Additionally, the decision to adopt cloud technologies should take into account additional IT resources and costs [30]-[32]. This may be due to the incremental introduction of the cloud for universities with insufficient ICT capital. In addition, a very long period of purchase of ICT technology in public universities and colleges will also hinder the acceptance of the cloud as the it requires bidding publicly and would obtain permission of the board of trustees on both overhead and procurement spending.

\subsection{Personal thoughts}

One of the reasons University 1 has implemented cloud infrastructure is that services can be accessed at any time and from any place. The transmission of data is also fast. The IT director, who has participated in University 1 interviews, agrees and acknowledges that engaging cloud services will provide university students, faculty and staff with effective communication channels. The interviewee clarified that cloud infrastructure provides a paperless collaboration mechanism.

University 2 IT faculty finds the benefit of cloud-based computing to be a significant technology. The resources offered by cloud will help improve literacy and attract students and faculty members to various modes of learning. But because of a poor internet connection, he explains that the classroom exercises can fall short. It is considered an important concern by the respondent. He added that the internet access of the city had a maximum bandwidth of $50 \mathrm{Mbps}$, which was not sufficient for many schools' heavy use requirements. University 2 is thus restricted from completely participating cloud practices in the classroom.

The IT director at University 3 is opposed to cloud adoption. She claims that cloud technology is useless for her institution's IT department due to the same problem, internet access speed. She considers cloud computing to be a waste of time since the services cannot be reached on time. She goes on to say:

"Even just logging into the computer, takes a lot of time. Without stable internet access, there's no way you can do something like that. Therefore, it would be quite challenging and hard for me to engage in cloud computing."

\section{CONCLUSION}

The study concluded that there were two significant factors identified: i) internet access speed; ii) a lack of knowledge of cloud technologies was discovered to be one of the most significant barriers to accepting cloud infrastructure in SUCs in the region. Personal perspectives are considered more relevant in bringing steps to use the cloud. Meanwhile, these findings can provide ISPs with perspectives into how to upgrade internet infrastructure and thereby provide high availability of service networks in a cost-effective manner. In order to make this happen, the university's administration, in collaboration with the IT leaders, may engage with ISPs and maybe analyze current broadband pricing and regulations.

To make cloud infrastructure more accessible: i) The university will hold or host trainings, conferences, or workshops for its faculty and staff in order to provide them with awareness of the significant benefits and potential risks of this technology, as well as to guide its future development; ii) The sufficiency of ICT infrastructures in universities has enticed academics, professors, and staff to pursue cloud computing; iii) School management should collaborate with key partners to strategize and explore solutions to the problems and concerns found in this research. Furthermore, budget is also thought to have played a larger role in the decision to use cloud providers. It is recommended to underfunded universities that the procurement program be revisited and proper planning be implemented so that investments in ICT technology do not go unused.

Moreover, this study also highlights the impact of cloud computing to SUCs: Cloud computing basically allows efficient, fast and effective means of transaction especially in this time of pandemic. It is more beneficial to SUCs or educational system which allows students and professors to both enjoy the accessibility of education amidst pandemic; professors can easily upload lessons and teaching materials while students can easily access the materials online, though the challenge lies in the connectivity of internet in the country. Administrators can easily collaborate with the entire academic community and even to its stakeholders, potential for collaboration even if not in face-to-face transaction. It is a perfect avenue to be productive and efficient which allows all processes be made possible to all members of the entire academic community, may it be students, professors, staff and even other stakeholders. 


\section{ACKNOWLEDGEMENTS}

The authors are grateful to the provision afforded by the Surigao Del Sur State University.

\section{REFERENCES}

[1] T. Branco Jr., F. De Sá-Soares, and A.L. Rivero, "Key Issues for the Successful Adoption of Cloud Computing," Procedia Computer Science, vol. 121, pp. 115-22, 2017, doi: 10.1016/j.procs.2017.11.016.

[2] M. Attaran, S. Attaran, and B.G. Celik, "Promises and Challenges of Cloud Computing in Higher Education: A Practical Guide for Implementation," Journal of Higher Education Theory and Practice, vol. 17, no. 6, pp. 20-38, 2017.

[3] S. Ashtari and A. Eydgahi, "Student Perceptions of Cloud Computing Effectiveness in Higher Education," 2015 2015 IEEE 18th International Conference on Computational Science and Engineering, 2015, pp. 184-191, doi: 10.1109/CSE.2015.36.

[4] P.K. Senyo, E. Addae, and R. Boateng, "Cloud computing research: A review of research themes, frameworks, methods and future research directions," International Journal of Information Management, vol. 38, no. 1, pp. 128-139, 2018, doi: 10.1016/j.ijinfomgt.2017.07.007.

[5] M. Al-Ruithe, E. Benkhelifa, and K. Hameed, "Current State of Cloud Computing Adoption - An Empirical Study in Major Public Sector Organizations of Saudi Arabia (KSA)," Procedia Computer Science, vol. 110, pp. 378-85, 2017, doi: 10.1016/j.procs.2017.06.080.

[6] A. Khayer, S. Talukder, Y. Bao, and Md. N. Hossain, "Cloud computing adoption and its impact on SMEs' performance for cloud supported operations: A dual-stage analytical approach," Technology in Society, vol. 60, 2020, doi: 10.1016/j.techsoc.2019.101225

[7] Y. Wang, "Innovative Learning Design for Online Language Learning: A Systems Design Framework," in Exploring Innovative Pedagogy in the Teaching and Learning of Chinese as a Foreign Language, vol. 15. Springer, Singapore, 2016, pp. 253-271.

[8] I. Arpaci, "Antecedents and consequences of cloud computing adoption in education to achieve knowledge management," Computers in Human Behavior, vol. 70, pp. 382-390, 2017, doi: 10.1016/j.chb.2017.01.024.

[9] A.A. Almazroi, H. Shen, and F. Mohammed, "The impact of trust on the adoption of cloud computing services by university students," in F. Saeed, N. Gazem, F. Mohammed, A. Busalim, Eds., Recent Trends in Data Science and Soft Computing. IRICT 2018. Advances in Intelligent Systems and Computing, vol 843. Springer, Cham, 2019, doi: 10.1007/978-3-319-99007-1_84.

[10] M.K. Juma and A. Tjahyanto, "Challenges of cloud computing adoption model for higher education level in Zanzibar (the case study of Suza and Zu)," Procedia Computer Science, vol. 161, pp. 1046-1054, 2019, doi: 10.1016/j.procs.2019.11.215.

[11] M.H. Raza, A.F. Adenola, A. Nafarieh, and W. Robertson, "The slow adoption of cloud computing and IT workforce," Procedia Computer Science, vol. 52, no. 1, pp. 1114-1119, 2015, doi: 10.1016/j.procs.2015.05.128.

[12] K. Njenga, L. Garg, A. K. Bhardwaj, V. Prakash, and S. Bawa, "The cloud computing adoption in higher learning institutions in Kenya: Hindering factors and recommendations for the way forward," Telematics and Informatics, vol. 38, pp. 225-246, 2019, doi: 10.1016/j.tele.2018.10.007.

[13] S. Tweneboah-Koduah, B. Endicott-Popovsky, and A. Tsetse, "Barriers to Government Cloud Adoption," International Journal of Managing Information Technology, vol. 6, no. 3, pp.1-16, 2014, doi: 10.5121/ijmit.2014.6301.

[14] K. Popović and Ž. Hocenski, "Cloud computing security issues and challenges," The 33rd International Convention MIPRO, 2010, pp. 344-349.

[15] O.C. Akin, T.M. Fagbola, C.Y. Daramola, "The Impact and Challenges of Cloud Computing Adoption on Public Universities in Southwestern Nigeria," International Journal of Advanced Computer Science and Applications, vol. 5, no. 8, pp. 13-19, 2014, doi: 10.14569/IJACSA.2014.050803.

[16] R.D. Raut, P. Priyadarshinee, B.B. Gardas, and M.K. Jha, "Analyzing the factors influencing cloud computing adoption using three stage hybrid SEM-ANN-ISM (SEANIS) approach," Technol Forecast Soc Change., vol. 134, pp. 98-123, 2018, doi: 10.1016/j.techfore.2018.05.020.

[17] K. Vu, K. Hartley, and A. Kankanhalli, "Predictors of cloud computing adoption: A cross-country study," Telematics and Informatics, vol. 52, 2020, doi: 10.1016/j.tele.2020.101426.

[18] A. Tashkandi and I. Al-Jabri, "Cloud Computing Adoption by Higher Education Institutions in Saudi Arabia: Analysis Based on TOE," 2015 International Conference on Cloud Computing (ICCC), 2015, pp. 1-8, doi: 10.1109/CLOUDCOMP.2015.7149634.

[19] H.M. Sabi, F.M.E. Uzoka, K. Langmia, and F.N. Njeh, "Conceptualizing a model for adoption of cloud computing in education," International Journal of Information Management, vol. 36, no. 2, pp. 183-191, 2016, doi: 10.1016/j.ijinfomgt.2015.11.010.

[20] W.J. Fan, S. Yang, H. Perros, and J. Pei, "A multi-dimensional trust-aware cloud service mechanism on evidential reasonig approach," International Journal of Automation and Computing, vol. 12, no. 2, pp. 208-219, 2015, doi: 10.1007/s11633-014-0840-3.

[21] Y.S. Chang, Y.H. Chien, K.C. Yu, H.C. Lin, and M.Y.C. Chen, "Students' innovative environmental perceptions and creative performances in cloud-based m-learning," Comput Human Behav., vol. 63, pp. 988-994, 2016, doi: 10.1016/j.chb.2016.06.032. 
[22] S. Das and M. Dayal, "Exploring determinants of cloud-based enterprise resource planning (ERP) selection and adoption: A qualitative study in the Indian education sector," Journal of Information Technology Case and Application Research, vol. 18, no. 1, pp. 11-36, 2016, doi: 10.1080/15228053.2016.1160733.

[23] O. Ali and V. Osmanaj, "The role of government regulations in the adoption of cloud computing: A case study of local government," Computer Law \& Security Review, vol. 36, Apr. 2020, doi: 10.1016/j.clsr.2020.105396.

[24] R. K. Yin, Case Study Research: Design and Methods. SAGE Publications, 2013.

[25] N. Alkhater, R. Walters, and G. Wills, "An empirical study of factors influencing cloud adoption among private sector organisations," Telematics and Informatics, vol. 35, no. 1, pp. 38-54, 2018, doi: 10.1016/j.tele.2017.09.017.

[26] M. Tarmidi, S.Z.A. Rasid, B. Alrazi, and R.A. Roni, "Cloud computing awareness and adoption among accounting practitioners in Malaysia," Procedia - Social and Behavioral Sciences, vol. 164, pp. 569-74, 2014, doi: 10.1016/j.sbspro.2014.11.147.

[27] S. Chaveesuk, P. Wutthirong, and W. Chaiyasoonthorn, "Cloud computing classroom acceptance model in Thailand higher education's institutes: A conceptual framework," ICIME 2018: Proceedings of the 2018 10th International Conference on Information Management and Engineering, 2018, pp. 141-145, doi: $10.1145 / 3285957.3285989$.

[28] B.N. Hwang, C.Y. Huang, C.L. Yang, "Determinants and their causal relationships affecting the adoption of cloud computing in science and technology institutions," Innovation Organization \& Management, vol. 18, no. 2, pp. 164-190, 2016, doi: 10.1080/14479338.2016.1203729.

[29] N. Ahmad, N. Hoda, and F. Alahmari, "Developing a cloud-based mobile learning adoption model to promote sustainable education," Sustainability, vol. 12, no. 8, p. 3126, 2020, doi: 10.3390/su12083126.

[30] A.M. AlBar and M.R. Hoque, "Factors affecting cloud ERP adoption in Saudi Arabia: An empirical study," Information Development, vol. 35, no. 1, pp. 150-164, 2019, doi: 10.1177/0266666917735677.

[31] A. S. M. Al-Rawahna, C-W. Hung, and S-C. Chen, "Readiness of Government Organizations for CloudComputing Age: An Empirical Evidence from Jordan," Journal of Business and Management Sciences, vol. 6, no. 4, pp. 152-162, 2018, doi: 10.12691/jbms-6-4-3.

[32] B. Ahn and H. Ahn, "Factors affecting intention to adopt cloud-based ERP from a comprehensive approach," Sustainability, vol. 12, no. 16, pp. 1-26, 2020, doi: 10.3390/su12166426. 